\title{
Mechanical properties of biopolymer-stabilised soil-based construction materials
}

\author{
S. MUGUDA*, S. J. BOOTH†, P. N. HUGHES \\ C. PERLOT\|, A. W. BRUNO** and D. GALLIPOLI††
}

\begin{abstract}
Soil-based construction materials are of interest as structural building materials due to their green credentials, as well as being present in many historical structures. For effective conservation of the latter, and to motivate greater uptake for new construction, understanding of the mechanical and hydraulic properties of these materials is in need of improvement. Earthen construction materials can be considered to be manufactured unsaturated soils, and advances in understanding can be made by considering them from a geotechnical point of view. This paper presents initial results from a major programme of testing, seeking improved properties for earthen construction materials, where unusual organic compounds have been employed as stabilisers. Two gums (guar and xanthan) used as stabilisers for a soil mixture are shown to have significant effects on certain mechanical properties, some of which can be explained, and other aspects which are in need of further investigation.
\end{abstract}

KEYWORDS: laboratory tests; partial saturation; suction

ICE Publishing: all rights reserved

\section{INTRODUCTION}

Earthen construction refers to the use of subsoil materials to create structural members, such as walls, and is distinguished from other forms of construction that use soils (e.g. earth dams) by the difference in environment - that is large surfaces open to the weather and consequently low water content. Techniques are both unit-based (e.g. adobe and compressed earth blocks) and in situ (e.g. rammed earth, pisé and cob). These methods of construction have been used by man for thousands of years and are coming under scrutiny for modern construction as they could offer low carbon and low embodied energy alternatives to construction using cement-based products or fired masonry (Jaquin \& Augarde, 2012). It is only in the last decade, however, that these materials have been correctly identified as geotechnical in nature - that is where frictional strength is key and unsaturated soil mechanics concepts are useful (Jaquin et al., 2009; Gallipoli et al., 2014, 2017; Beckett et al., 2017). A key barrier to wider adoption of these materials for modern construction, especially in temperate zones such as northern Europe, is their poorly understood mechanical properties. Modern earthen materials often use stabilisers

Manuscript received 25 July 2017; first decision 1 November 2017; accepted 5 November 2017.

Published online at www.geotechniqueletters.com on 16 November 2017.

*Department of Engineering, Durham University, Durham, UK; Laboratoire SIAME, Fédération IPRA, Université de Pau et des Pays de l'Adour, Anglet, France (Orcid:0000-0003-3108-5716).

$\dagger$ (formerly) Department of Engineering, Durham University, Durham, UK.

tDepartment of Engineering, Durham University, Durham, UK (Orcid:0000-0002-7260-794X).

§Department of Engineering, Durham University, Durham, UK (Orcid:0000-0002-5576-7853).

||Laboratoire SIAME, Fédération IPRA, Université de Pau et des

Pays de l'Adour, Anglet, France.

**Laboratoire SIAME, Fédération IPRA, Université de Pau et des

Pays de l'Adour, Anglet, France (Orcid:0000-0002-1408-4132).

†'Laboratoire SIAME, Fédération IPRA, Université de Pau et des

Pays de l'Adour, Anglet, France (Orcid:0000-0003-1576-0742). such as cement to provide bonding, but this clashes with their green credentials and alternative stabilisers are therefore keenly sought.

Biopolymers are naturally occurring polymers, typically from plant sources, which have been previously used as viscosifiers (Plank, 2004). Recently, researchers have explored the possibility of using biopolymers as soil stabilisers, and it has been reported that, when added to soil biopolymers have reduced soil permeability (Bouazza et al., 2009; Aminpour \& O'Kelly, 2015), increased shear strength (Cabalar \& Canakci, 2011; Chang et al., 2015b, 2015c), improved compressibility (Latifi et al., 2016) and enhanced durability (Qureshi et al., 2017). Biopolymer stabilisation changes soil properties by the formation through hydration of 'hydrogels'. On drying, the water molecules tend to escape from polymer chains leading to the formation of complexes of linked polymer chains. In addition, during drying, the hydrogels transform from what is termed a 'rubbery' to a 'glassy' state (Eichler et al., 1997; Ayeldeen et al., 2016). When mixed in soil, the hydrogels form bonds between soil particles and free water through hydrogen and/or ionic bonding depending on the intrinsic properties of the biopolymer used (Chudzikowski, 1971; Katzbauer, 1998). From the findings in these previous works, it is clear that biopolymers may have potential as stabilisers in soil-based construction materials, providing additional shear strength and stiffness, without the carbon footprint of a cement stabiliser. Indeed, the production of xanthan gum actually consumes carbon dioxide (Chang et al., 2016). This paper presents initial results from a campaign of laboratory testing assessing the mechanical properties of biopolymer-treated materials, and speculates on potential explanations.

\section{EXPERIMENTAL PROGRAMME}

A base soil mixture comprising 20\% kaolin, 70\% sharp sand and 10\% gravel by mass (denoted 2-7-1) was chosen as it complies with the requirements for earthen construction materials given in earlier publications (Olivier \& Mesbah, 1987; Houben \& Guillaud, 1994; Venkatarama Reddy \& 
Table 1. Physical properties of the unstabilised soil mixture used in this study

\begin{tabular}{l|c|c|c|c|c|c|c|c}
\hline Soil & Clay: $\%$ & Silt: $\%$ & Sand: $\%$ & Gravel: $\%$ & Liquid limit: $\%$ & Plastic limit: $\%$ & OWC: $\%$ & $\gamma_{\mathrm{d}, \max }: \mathrm{kN} / \mathrm{m}^{3}$ \\
\hline $2-7-1$ & 16 & 4 & 70 & 10 & $36 \cdot 2$ & $18 \cdot 4$ & $9 \cdot 8$ & $19 \cdot 62$ \\
\hline
\end{tabular}

$\gamma_{\mathrm{d}, \max }:$ maximum dry density

Jagadish, 1995; Beckett \& Augarde, 2012) and is a combination widely investigated. Atterberg limits and compaction characteristics (using the $2.5 \mathrm{~kg}$ Proctor test) obtained in accordance with British Standards (BS 1377-2 (BSI, 1990a); BS 1377-4 (BSI, 1990b)) for the unamended soil mixture are given in Table 1. Commercially available guar and xanthan gums were chosen as biopolymer stabilisers in this study due to their availability and good stability properties with respect to temperature and $\mathrm{pH}$ variations (Mudgil et al., 2011). As indicated in literature when added within a range of $3.0 \%$, the biopolymer-treated soil has comparable performance with $10 \%$ cement-treated soil (Chang et al., 2015a; Qureshi et al., 2017), hence the biopolymer content in study was added in the range of $0 \cdot 5-3 \cdot 0 \%$ by mass of the dry unamended sample.

The cylindrical specimens $(38 \mathrm{~mm}$ diameter $\times 76 \mathrm{~mm}$ height) were tested in unconfined compression (UC), and 'bowtie' specimens were tested in tension using the procedure outlined in Stirling et al. (2015). All the ingredients (the base soil mix and biopolymer) were dry mixed initially and then the water equivalent to the optimum water content (OWC) was added. During preparation of the treated samples, it was necessary to add additional water above the OWC in order to make the soil mix workable. The amount of additional water required varied with respect to the biopolymer used and can be explained by the different chemical compositions of the gums as discussed in Torres et al. (2012), wherein the polymer chains in guar have a lower water-absorption capacity than in xanthan, and therefore need more water to hydrate and hence achieve a workable soil mix. The amounts of additional water needed for both biopolymers are given in Table 2. All the samples were statically compacted to achieve the initial dry density of $19.62 \mathrm{kN} / \mathrm{m}^{3}$ having a porosity of $16.98 \%$ and pore void volume of $14.63 \mathrm{~cm}^{3}$. However, due to the addition of biopolymer there was slight variation in the initial dry densities achieved and corresponding porosity and pore space volume values. Following preparation, samples were left to cure by drying to the laboratory atmosphere (relative humidity $(\mathrm{RH})$ of $50 \%$ and temperature of $21^{\circ} \mathrm{C}$ ) and were then tested after 7 and 28 days. Finally, the water content and total suction (using a WP4C potentiometer) were measured on portions of the remains. For comparison, identical tests were carried out on samples of the unamended soil after 7 days of air curing and on samples stabilised with $8.0 \%$ cement by mass after 7 and 28 days of air curing. Similar to biopolymer-stabilised samples, air curing took place inside the laboratory atmosphere.

\section{RESULTS AND DISCUSSION}

Axial stress/strain plots recorded during the UC tests are shown in Fig. 1. The differences in stiffness at low axial strains are due to sample bedding in and the key conclusions should be drawn from the results $>0 \cdot 5 \%$ strain. After 7 days of curing, for both guar- and xanthan-treated specimens, there is an appreciable difference in the $>0.5 \%$ stiffness between different concentrations, with higher concentrations leading to higher stiffness. At 28 days curing, however, these differences are no longer evident. These variations of the
Table 2. Amount of additional water needed for different biopolymer contents

\begin{tabular}{l|c|c|c}
\hline \multirow{2}{*}{$\begin{array}{l}\text { Serial } \\
\text { number }\end{array}$} & $\begin{array}{c}\text { Biopolymer } \\
\text { content }\end{array}$ & \multicolumn{2}{|c}{$\begin{array}{c}\text { Additional water added above } \\
\text { OWC: } \%\end{array}$} \\
\cline { 3 - 4 } & & Guar gum & Xanthan gum \\
\hline 1 & $0 \cdot 50$ & $0 \cdot 50$ & $0 \cdot 25$ \\
2 & $1 \cdot 00$ & $1 \cdot 00$ & $0 \cdot 50$ \\
3 & $1 \cdot 50$ & $1 \cdot 50$ & $0 \cdot 75$ \\
4 & $2 \cdot 00$ & $2 \cdot 00$ & $1 \cdot 00$ \\
5 & 3.00 & $3 \cdot 00$ & $1 \cdot 50$ \\
\hline
\end{tabular}

stiffness provide evidence of the change of state of the hydrogel products formed by the biopolymers, which is discussed in more detail below.

UC peak strength is plotted against \% stabiliser in Fig. 2 for both biopolymers, where it can be seen that an addition of $2 \%$ guar provides soil with compressive strength higher than the cement-stabilised sample: approximately $30 \%$ higher after 7 days and 35\% after 28 days. After 7 days, xanthan at $1.5 \%$ produces approximately the same strength as the cement-stabilised specimen and, at $2 \%$, the strength becomes approximately $50 \%$ higher than the cementstabilised specimens. However, xanthan specimens tested at 28 days showed reductions in strength compared to the 7 day specimens. For the range of percentage stabiliser additions, both plots show increasing strength, with no optimum treatment concentration reached within the range tested, although all treated samples improve on the unamended soil. Given the variation in strength behaviour between stabiliser concentrations and curing periods discussed above, the primary mechanisms controlling strength would appear to be different to that driving stiffness.

The tensile test results are shown in Fig. 3 indicating a clear relationship between stabiliser concentration and tensile strength. The error bars show the greater variation for these tests that can be explained by the different modes of failure. Tensile strength will be critically affected by the presence and nature of microcracking, which will vary between samples and be difficult to predict or control. Shear failure in the UC tests show much less scatter as the resistance to failure is more distributed over a surface. Unlike the UC results, the tensile strength of the guar samples reduces over time whereas the xanthan samples increase over time. At 7 days, all concentrations of biopolymer lead to higher tensile strengths than unamended soil, but lower than for the cement-treated soil. At 28 days, the strength of the $2 \%$ xanthan gum-treated soil exceeds the cement-treated soil by $38 \%$. The differences in the relative performances of cement and biopolymer-treated samples when tested in tension, as opposed to compression, suggest that the stabilising mechanisms through which compressive and tensile resistance is mobilised within the specimens are different.

As noted in Jaquin et al. (2009), a significant component of the strength of unstabilised soil-based construction materials can be linked to the suction present due to the very low in situ water contents and presence of fine soil fractions. Zhao (2014) and Cao et al. (2017) using Tempe cell 


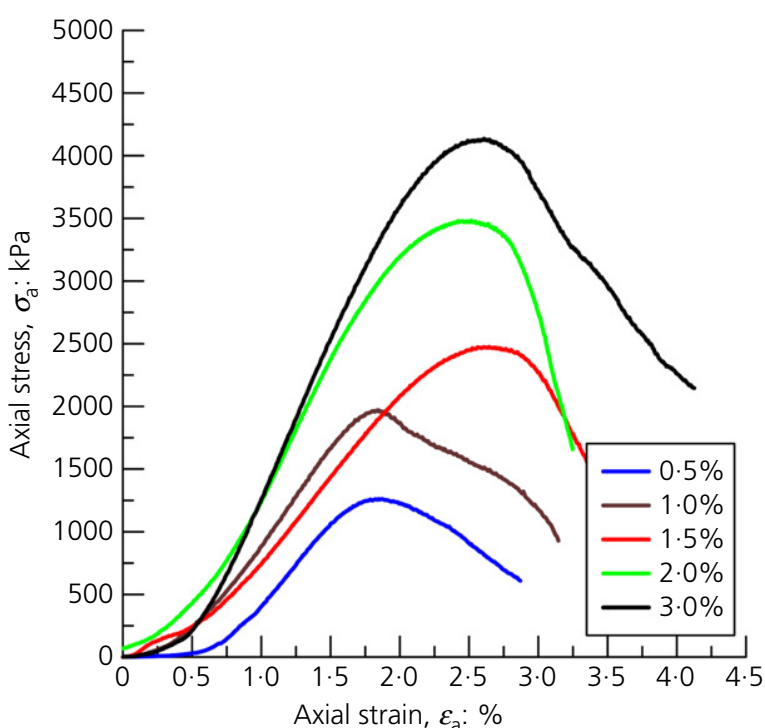

(a)

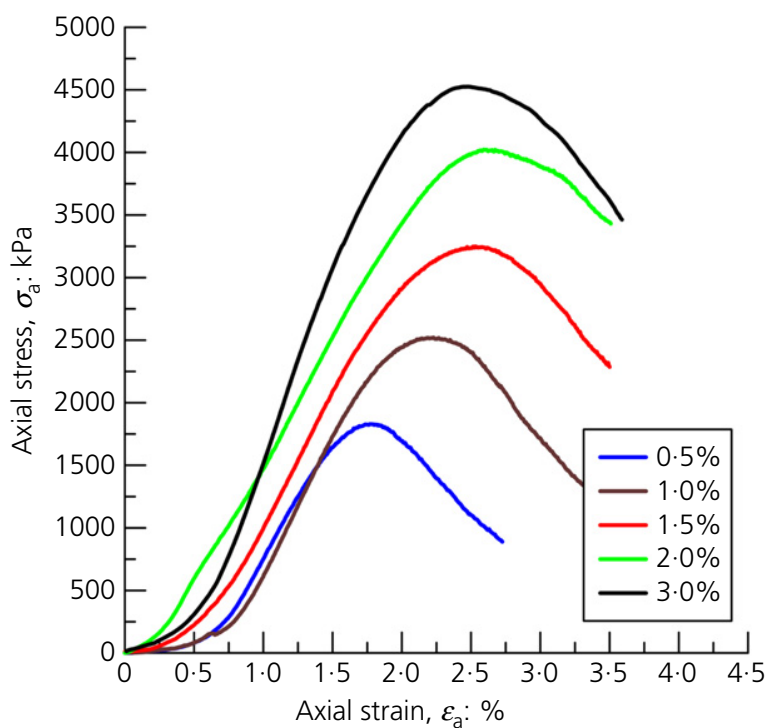

(c)

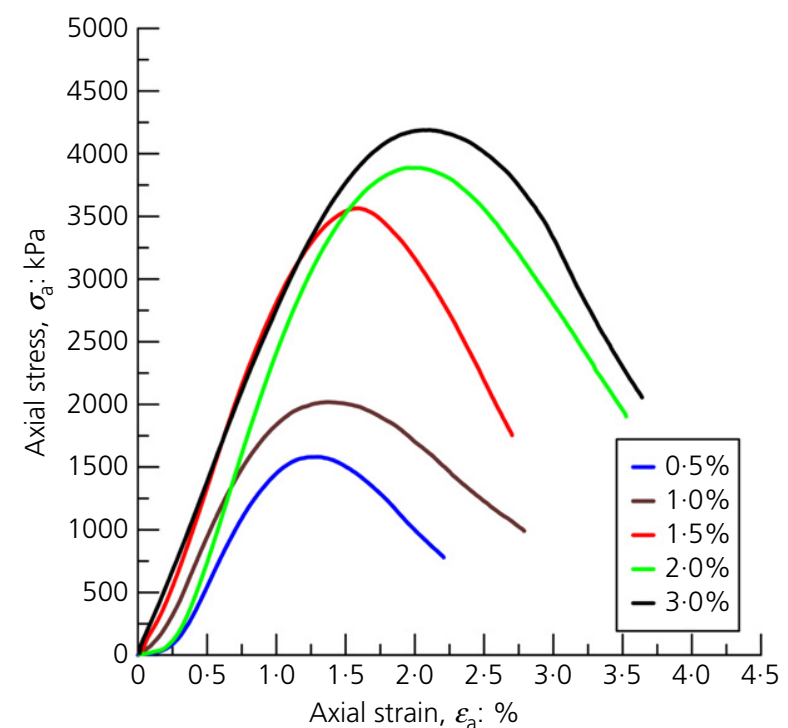

(b)

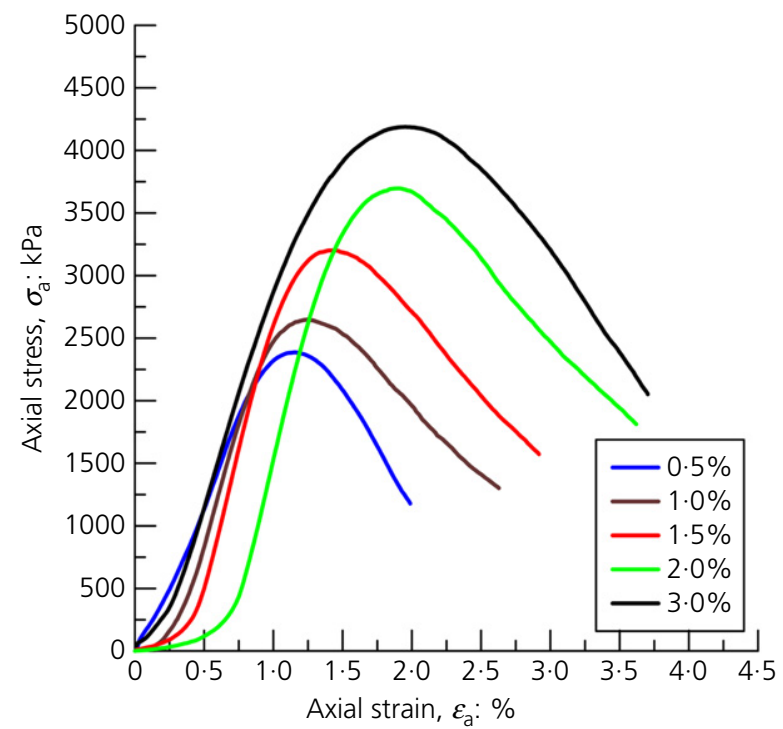

(d)

Fig. 1. Stress-strain behaviour in UC tests (for each \% stabiliser only one test among three replicates is shown): (a) guar gum, 7 days, (b) guar gum, 28 days, (c) xanthan gum, 7 days, (d) xanthan gum, 28 days

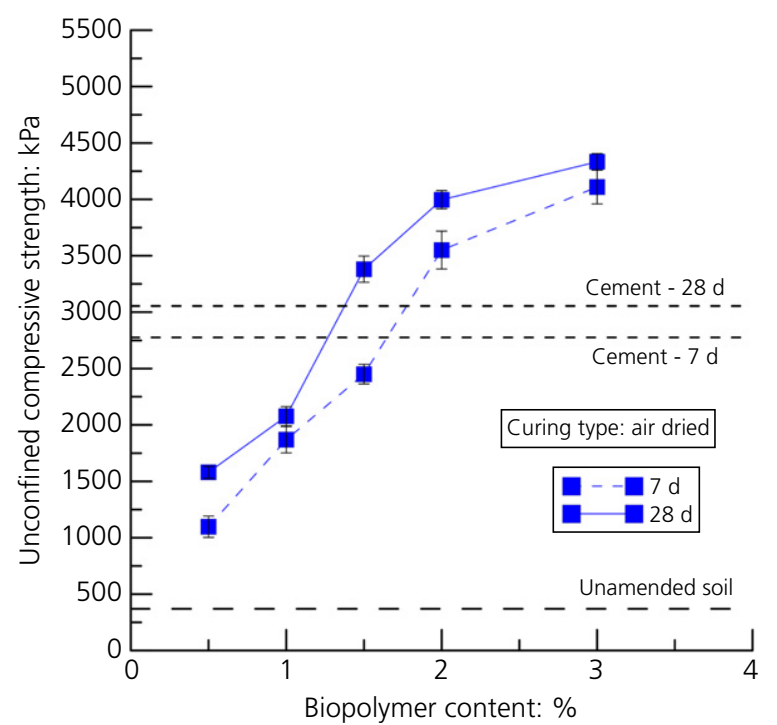

(a)

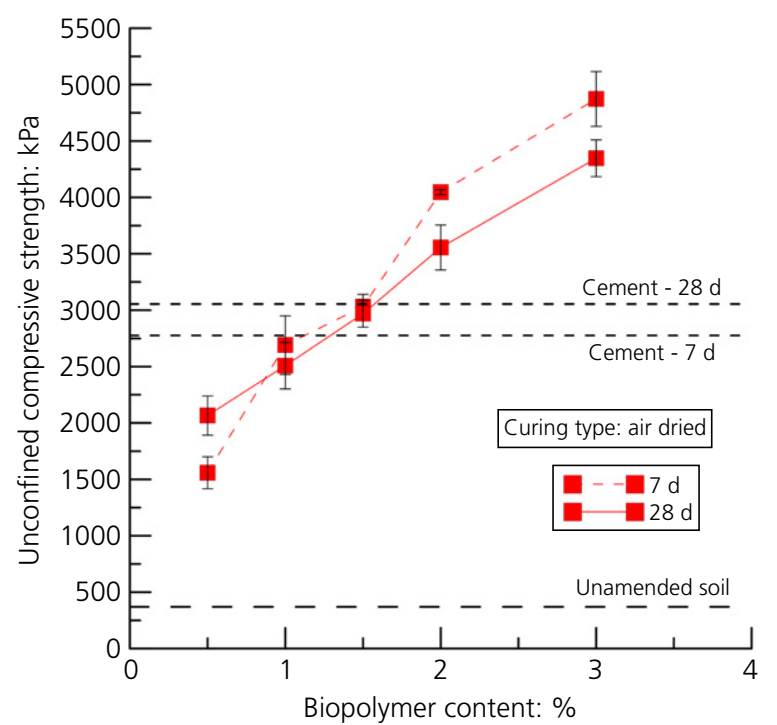

(b)

Fig. 2. UC test results (average values of peak strength based on three replicates), (a) guar gum, (b) xanthan gum 


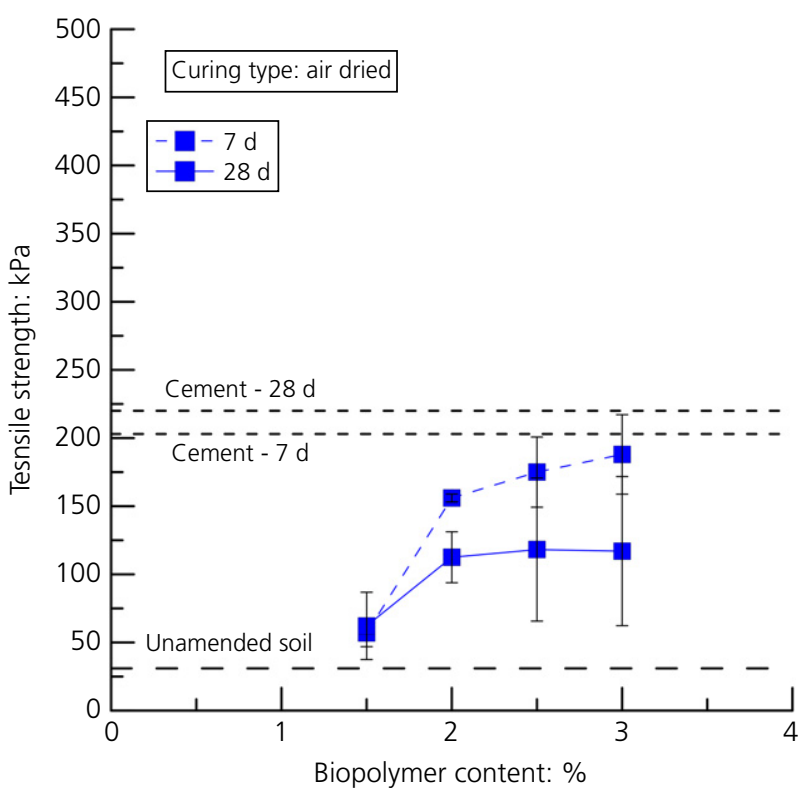

(a)

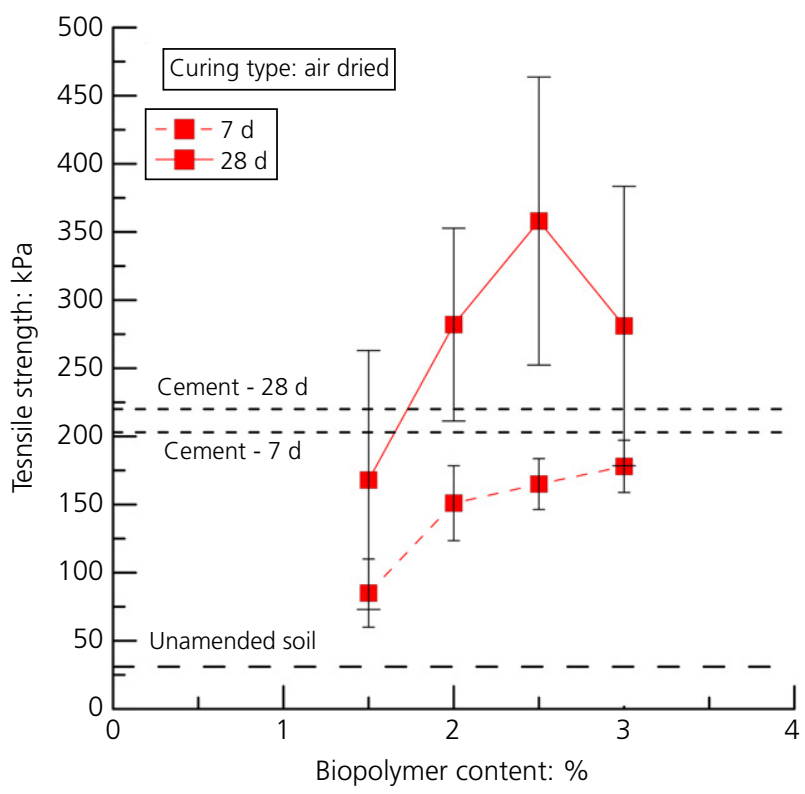

(b)

Fig. 3. Tensile test results (average values of tensile strength based on three replicates), (a) guar gum, (b) xanthan gum

measured soil water characteristic curves (SWCCs) for poorly graded sand initially saturated with water and biopolymer solutions. It was noted that higher matric suction was needed to desaturate sand treated with xanthan solution at $2 \mathrm{~g} / \mathrm{l}$ concentration, indicating that addition of biopolymer will have an effect on suction of treated soil (Fig. 4). In addition, Chang et al. (2015c) note that the strength of the biopolymer-stabilised soil is dependent on the water content, although that point is not relevant to this study where the end application is a material dried to the environmental equilibrium. It is therefore instructive to measure suction for the materials tested here to try to understand the effect of biopolymer addition on suction and potential strength. Fig. 5 shows suction and the water content data recorded immediately after UC strength testing. Some observations are as follows:

- All biopolymer-treated samples exhibit higher suctions than the unamended and cement-treated specimens indicating a contribution from osmotic suction from biopolymer products (indeed suctions are evident in samples of plain hydrated biopolymer confirming this). The effect is not dependent on $\%$ stabiliser at 28 days but at 7 days there is a variation indicating that as the hydrogels change state, their contribution to suction varies.

- At 28 days, the water content of guar gum-treated samples was higher than 7 days, while for xanthan-treated samples it was lesser. This variation may be due to their interaction with the surrounding atmosphere. As noted by Kocherbitov et al. (2010), the vapour sorption/diffusion of a biopolymer is dependent on its state, temperature and humidity. Hence, by the end of 28 days, guar gum stabilises through water absorption from the atmosphere, while xanthan gum, uses as much free water as it needs, with the remainder of the water evaporating.

- At 7 days, the suction measured in the unamended samples corresponds to the value calculated using Kelvin's equation, given the average $\mathrm{RH}$ and temperature in the laboratory. For the amended samples, however, suction equilibrates at a higher level, between 125 and $135 \mathrm{MPa}$, further confirming osmotic suction

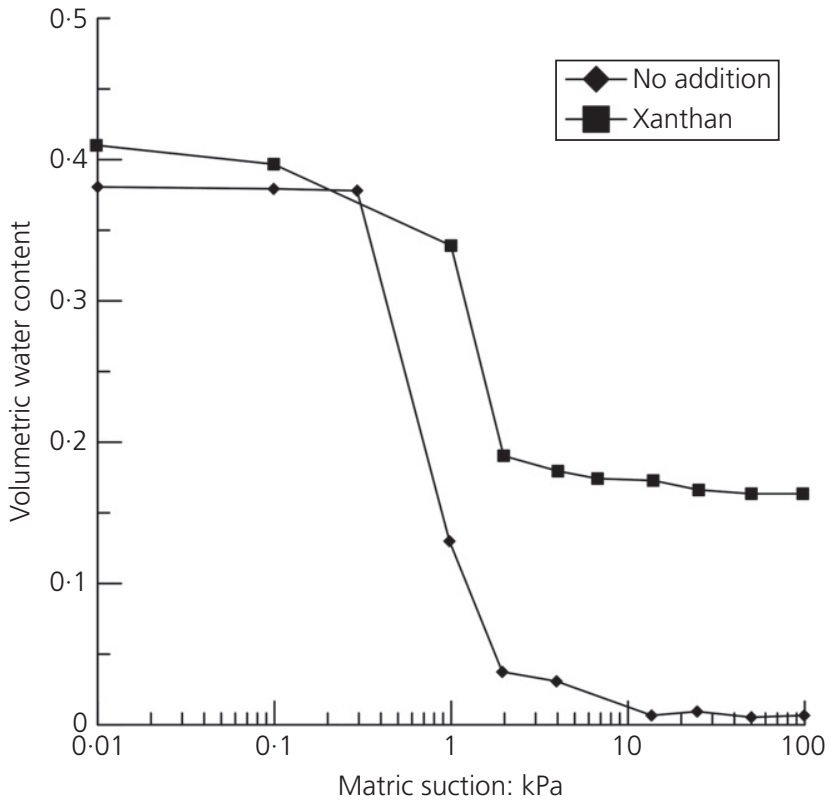

Fig. 4. Changes in suction due to polymer treatment (after Zhao, 2014)

contributions from the presence of the biopolymer products.

- Water contents increase with \% stabiliser throughout, which is linked to the additional water required to achieve workable mixes.

- After 7 days, high suctions are linked to low water contents for both gums indicating a more significant contribution to suction from pore water than at 28 days.

When the suction results are reviewed in parallel with the UC strength data (Fig. 2) clear conflicts are evident. For the guar samples, suctions are seen to reduce between 7 and 28 days, while UC strengths increase. Equally, for the xanthan samples, suctions increase while UC strengths decrease. Changes in UC strength must therefore be explained through additional mechanisms besides suction-induced capillary 


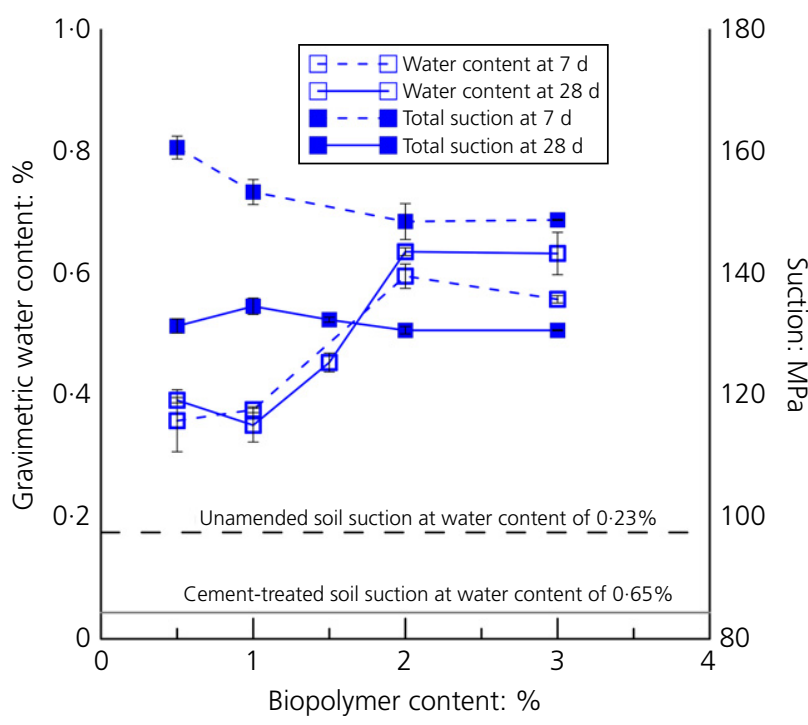

(a)

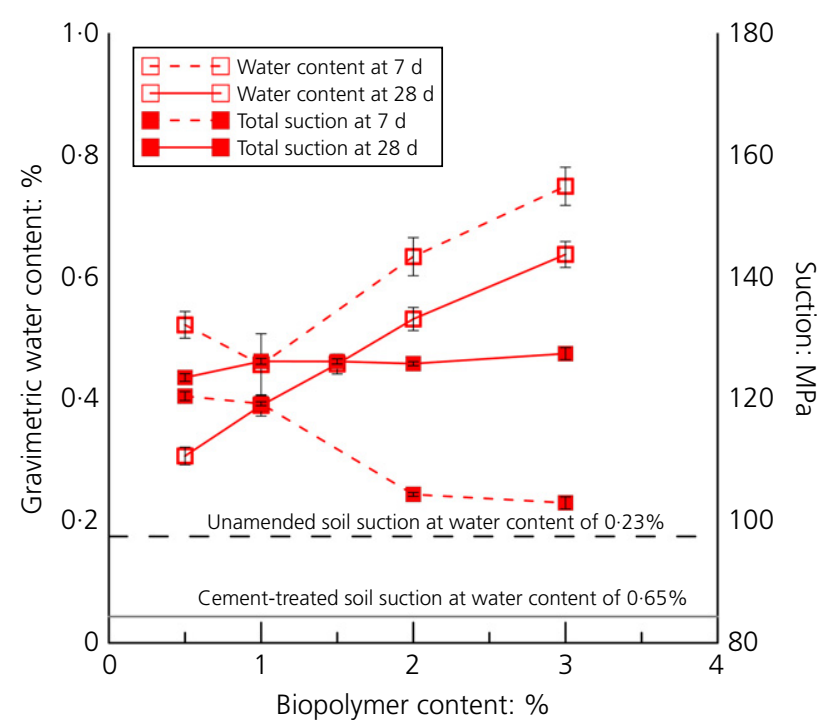

(b)

Fig. 5. Suction and water content values at ends of UC tests (a) guar gum, (b) xanthan gum

bonding. Conversely, suction changes shown in Fig. 5 correspond well with changes in the tensile strength of the biopolymer-treated soils in that decreases in suction of guar gum samples after 28 days correspond to lower strengths, and increases in suction in xanthan gum samples correspond to higher strengths. The higher suctions and strengths of the biopolymer-treated specimens compared with the untreated specimens suggest that the strength gains are caused by a combination of suction (mainly osmotic) and hydrogel bonding. The nature of the bonding of these hydrogels with soil particles depends on the biopolymer type.

Guar gum, being a neutrally charged polysaccharide with large hydroxyl groups (Chudzikowski, 1971), forms a network of hydrogels between soil particles and free water by way of hydrogen bonds (Chen et al., 2013). At 7 days, these hydrogels (predominantly being in rubbery state) may contribute to matric suction and hence the stabiliser content contributes to the measured suction (Fig. 5). Thereby, the combination of suction and hydrogels contribute to the observed higher compressive strength of the soil. Tensile strength is also believed to be driven by a combination of suction and hydrogel bonding. However, as hydrogels are more elastic and weaker than cement bonds in tension, the tensile strengths are lower than the cement-treated specimens. Once the hydrogels transform to a glassy state, the suctions tend to reduce and reach constant values irrespective of the stabiliser content (Fig. 5). However, the increase in compressive strength and stiffness may be attributed to the network of hydrogels now in a glassy state connecting the soil particles. Being a weaker chemical bond, the hydrogen bonds may not contribute to tensile strength with ageing.

Xanthan gum is an anionic polysaccharide (Katzbauer, 1998; Garcia-Ochoa et al., 2000) and the gum may interact with cations of the clay portion of the soil mix to form chemically stronger ionic bonds in addition to hydrogen bonds (Chang et al., 2015b). This combination of ionic and hydrogen bonds will result in better aggregation of the soil particles (Chen et al., 2013). Similar to guar gum, at 7 days, the combination of suction and hydrogel bonding contributes to both compressive and tensile behaviour of xanthantreated soils. While there is a slight decrease in compressive strength at 28 days, ionic bonding and transformation of hydrogels is reflected in higher suction which in turn results in higher stiffness (Fig. 1) and increases in tensile strength with time for xanthan-treated soils.

\section{CONCLUSIONS}

The initial results presented here appear to show that significant improvements to the mechanical properties of soil-based construction materials can be obtained using guar and xanthan gum biopolymers as stabilisers. General trends are explained and areas of contradiction highlighted. Additional investigation is ongoing, to determine the nature of the bonding in the treated soils.

\section{ACKNOWLEDGEMENTS}

The authors acknowledge the support of the European Commission through the Marie Skłodowska-Curie Innovative Training Networks (ITN-ETN) project TERRE 'Training Engineers and Researchers to Rethink geotechnical Engineering for a low carbon future' (H2020-MSCA-ITN-2015-675762).

\section{REFERENCES}

Aminpour, M. \& O'Kelly, B. C. (2015). Applications of biopolymers in dam construction and operation activities. In Second international Dam World Conference (DW2015) (eds C. Pina, E. Portela, L. Caldeira, A. Batista, I. Dias and R. Santos), pp. 937-946. Lisbon, Portugal: LNEC.

Ayeldeen, M. K., Negm, A. M. \& El Sawwaf, M. A. (2016). Evaluating the physical characteristics of biopolymer/soil mixtures. Arabian J. Geosci. 9, No. 5, 329-339.

Beckett, C. \& Augarde, C. (2012). The effect of humidity and temperature on the compressive strength of rammed earth. In Unsaturated soils: research and applications (eds. C. Mancuso, C. Jommi and F. D'Onza), pp. 287-292. Berlin, Heidelberg: Springer.

Beckett, C. T. S., Augarde, C. E., Easton, D. \& Easton, T. (2017). Strength characterisation of soil-based construction materials. Géotechnique, https://doi.org/10.1680/jgeot.16.P.288.

Bouazza, A., Gates, W. P. \& Ranjith, P. G. (2009). Hydraulic conductivity of biopolymer-treated silty sand. Géotechnique 59, No. 1, 71-72, http://dx.doi.org/10.1680/geot.2007.00137.

BSI (1990a). BS 1377-2: Methods of test for soils for civil engineering purposes-Part 2: Classification tests. BSI, London, UK.

BSI (1990b). BS 1377-4: Methods of test for soils for civil engineering purposes-Part 4: Compaction tests. BSI, London, UK.

Cabalar, A. F. \& Canakci, H. (2011). Direct shear tests on sand treated with xanthan gum. Proceedings of the ICE-ground 
improvement 164, No. 2, 57-64, http://dx.doi.org/10.1680/ grim.800041.

Cao, J., Jung, J., Song, X. \& Bate, B. (2017). On the soil water characteristic curves of poorly graded granular materials in aqueous polymer solutions. Acta Geotech., 1-14, http://dx.doi. org/10.1007/s11440-017-0568-7.

Chang, I., Jeon, M. \& Cho, G. (2015a). Application of microbial biopolymers as an alternative construction binder for earth buildings in underdeveloped countries, 2015, 1-9, http://dx.doi. org/10.1155/2015/326745.

Chang, I., Im, J., Prasidhi, A. K. \& Cho, G. C. (2015b). Effects of xanthan gum biopolymer on soil strengthening. Constr. Build. Mater. 74, No. 10, 65-72.

Chang, I., Prasidhi, A. K., Im, J. \& Cho, G. C. (2015c). Soil strengthening using thermo-gelation biopolymers. Constr. Build. Mater. 77, No. 2015, 430-438, http://dx.doi.org/10.1016/ j.conbuildmat.2014.12.116.

Chang, I., Im, J. \& Cho, G. C. (2016). Introduction of microbial biopolymers in soil treatment for future environmentally-friendly and sustainable geotechnical engineering. Sustainability 8, No. 3, 251.

Chen, R., Zhang, L. \& Budhu, M. (2013). Biopolymer stabilization of mine tailings. J. Geotech. Geoenviron. Engng 139, No. 10 , 1802-1807.

Chudzikowski, R. J. (1971). Guar gum and its applications. J. Soc. Cosmet. Chem. 22, No. 1, 43-60.

Eichler, S., Ramon, O., Ladyzhinski, I., Cohen, Y. \& Mizrahi, S. (1997). Collapse processes in shrinkage of hydrophilic gels during dehydration. Food Res. Int. 30, No. 9, 719-726.

Gallipoli, D., Bruno, A. W., Perlot, C. \& Salmon, N. (2014) Raw earth construction: is there a role for unsaturated soil mechanics. London, UK: Taylor \& Francis Group.

Gallipoli, D., Bruno, A. W., Perlot, C. \& Mendes, J. (2017) A geotechnical perspective of raw earth building. Acta Geotech. 12, No. 3, 463-478.

Garcia-Ochoa, F., Santos, V. E., Casas, J. A. \& Gomez, E. (2000). Xanthan gum: production, recovery, and properties. Biotechnol. $A d v$. 18, No. 7, 549-579.

Houben, H. \& Guillaud, H. (1994). Earth construction: a comprehensive guide. London, UK: Intermediate Technology Publications.

Jaquin, P. \& Augarde, C. (2012). Earth building: history, science and conservation. Bracknell, UK: IHS BRE Press.
Jaquin, P. A., Augarde, C. E., Gallipoli, D. \& Toll, D. G. (2009). The strength of unstabilised rammed earth materials. Géotechnique 59, No. 5, 487-490, http://dx.doi.org/10.1680/ geot.2007.00129.

Katzbauer, B. (1998). Properties and applications of xanthan gum. Polymer Degrad. Stabil. 59, No. 1-3, 81-84.

Kocherbitov, V., Ulvenlund, S., Briggner, L. E., Kober, M. \& Arnebrant, T. (2010). Hydration of a natural polyelectrolyte xanthan gum: Comparison with non-ionic carbohydrates. Carb. Polymers 82, No. 2, 284-290.

Latifi, N., Horpibulsuk, S., Meehan, C. L., Abd Majid, M. Z., Tahir, M. M. \& Mohamad, E. T. (2016). Improvement of problematic soils with biopolymer - an environmentally friendly soil stabilizer. J. Mater. Civil Engng 29, No. 2, 04016204-104016204-11

Mudgil, D., Barak, S. \& Khatkar, B. S. (2011). Guar gum: processing, properties and food applications - a review. J. Food Sci. Technol. 51, No. 6, 409-418.

Olivier, M. \& Mesbah, A. (1987). Influence of different parameters on the resistance of earth, used as a building material In International conference on mud architecture, Trivandrum, India, pp. 2-8, Rue maurice Audin, France: Ecole Nationale Des travaux Publics De L'etat.

Plank, J. (2004). Applications of biopolymers and other biotechnological products in building materials. Appl. Microbiol. Biotechnol. 66, No. 1, 1-9.

Qureshi, M. U., Chang, I. \& Al-Sadarani, K. (2017). Strength and durability characteristics of biopolymer-treated desert sand. Geomech. Engng 12, No. 5, 785-801.

Stirling, R. A., Hughes, P., Davie, C. T. \& Glendinning, S. (2015). Tensile behaviour of unsaturated compacted clay soils - a direct assessment method. Appl. Clay Sci. 112-113, 123-133, http:// dx.doi.org/10.1016/j.clay.2015.04.011.

Torres, M. D., Moreira, R., Chenlo, F. \& Vázquez, M. J. (2012). Water adsorption isotherms of carboxymethyl cellulose, guar, locust bean, tragacanth and xanthan gums. Carb. Polymers 89, No. 2, 592-598.

Venkatarama Reddy, B. V. \& Jagadish, K. S. (1995). Influence of soil composition on the strength and durability of soil-cement blocks. Indian Concrete J. 69, No. 9, 517-524.

Zhao, X. (2014). Measurements and transient multistep outflow simulation of soil-water characteristic curve for soils modified with biopolymers. Master's thesis, Missouri University of Science and Technology, Rolla, MO, USA.

\section{HOW CAN YOU CONTRIBUTE?}

To discuss this paper, please submit up to 500 words to the editor at journals@ice.org.uk. Your contribution will be forwarded to the author(s) for a reply and, if considered appropriate by the editorial board, it will be published as a discussion in a future issue of the journal. 